\title{
STUDI KASUS: OBSERVASI PERBAIKAN LUKA PADA PASIEN WOUND DEHISCENCE DENGAN NEGATIVE PRESSURE WOUND THERAPY (NPWT) DI RUANG KEMUNING V RSUP Dr. HASAN SADIKIN BANDUNG
}

\author{
Heri Budiawan, Cahyo Nugroho², Ria Inriyana ${ }^{3 *}$, Urip Rahayu ${ }^{4}$, Kusman Ibrahim ${ }^{5}$, \\ Nandang Mustari Aji $\mathbf{6}^{\mathbf{p}}$ \\ ${ }^{1}$ Departemen Keperawatan Medikal Bedah, Fakultas Keperawatan, Universitas Padjadjaran \\ ${ }^{2}$ Perawat Ruang Kemuning Lantai 5, RSUP Dr. Hasan Sadikin Bandung
}

Corresponding author: potrethery@gmail.com

\begin{abstract}
Abstrak
Manajemen bedah dengan sistem tekanan negatif atau negative pressure wound therapy (NPWT) ini dapat menjadi pendekatan baru untuk mengurangi komplikasi luka seperti wound dehiscence. Didapatkan beberapa penelitian mengenai perbaikan luka setelah dilakukan intervensi NPWT, namun sedikit yang mengungkap secara keseluruhan dengan memaparkan berdasarkan data demografi, faktor-faktor wound dehiscence, dan observasi perbaikan luka pada pasien wound dehiscence dengan NPWT. Metode yang digunakan yaitu informed consent, pengumpulan data melalui data primer dan sekunder, lalu dokumentasi. Kriteria inklusi pada studi kasus ini yaitu responden dengan usia $>18$ tahun, post operasi dengan infeksi akut, infeksi luka post operasi $<3$ minggu, dan terpasang NPWT. Didapatkan sampel pada studi kasus ini terdiri dari 2 orang. Data demografi menunjukkan bawa jenis kelamin, usia, lama rawat dan lokasi luka berpengaruh terhadap perbaikan luka. Faktorfaktor wound dehiscence terdapat pengaruh yaitu hipoalbumin, anemia, imobilisasi, dan penyakit penyerta, dimana untuk penyakit penyerta hanya terdapat pada pasien 2 . Pengkajian luka pada post NPWT hari ke 6 yaitu lokasi, eksudat, kulit sekitar luka, dan terapi mempengaruhi terhadap perbaikan luka. Simpulan, perbaikan luka pada pasien 1 post pemasangan NPWT terlihat derajat perbaikan yang signifikan ditandai dengan adanya granulasi, pengurangan eksudat sesuai dengan konsep tahapan perbaikan luka. Namun pada pasien 2 pada post 6 hari pemasangan NPWT belum terlihat adanya perbaikan yang signifikan ditandai dengan belum terlihatnya adanya granulasi pada luka tersebut. Keterlambatan perbaikan luka pada pasien 2 dikaitkan dengan faktor penyakit penyerta (diabetes mellitus tipe 2), status vaskularisasi dan oksigenasi.
\end{abstract}

Kata kunci: perbaikan luka, NPWT, wound dehiscence

\begin{abstract}
Surgical management with negative pressure wound therapy (NPWT) can be a new approach to reduce wound complications such as wound dehiscence. There were several studies regarding wound repair after NPWT intervention, but few revealed it as a whole by explaining based on demographic data, wound abnormalities factors, and observation of wound repair in dehiscence wound patients with NPWT. The method used is through primary data and secondary data. The inclusion criteria in this case study were respondents aged $>18$
\end{abstract}


years, postoperative acute infection, postoperative wound infection $<3$ weeks, and NPWT attached. The sample in this case study consisted of 2 respondents. Demographic data show that gender, age, length of stay and location of the wound have an effect on wound repair. Factors that affect wound dehiscence are hypoalbumin, anemia, immobilization, and comorbidities, where for comorbidities only in patients 2. Wound assessments after NPWT day 6 were assessed from the location, exudates, skin around the wound, and therapy affected improvement. wound. In conclusion, the wound repair in patient 1 after NPWT insertion shows a significant degree. However, in patient 2 at 6 days post NPWT installation, there was no significant improvement which was indicated by no visible granulation in the wound. Delay in wound repair in patient 2 was associated with comorbidities (type 2 diabetes mellitus), vascular status and oxygenation.

Keywords: wound care, NPWT, wound dehiscence

\section{Pendahuluan}

Pada tahun 2012 di Indonesia, tindakan operasi mencapai 1,2 juta jiwa dan diperkirakan $32 \%$ diantaranya merupakan tindakan bedah laparatomi (Kemenkes RI, 2013). Laparatomi merupakan jenis operasi bedah mayor yang dilakukan di daerah abdomen (Sjamsuhidajat \& Jong, 2005). Selain luka operasi laparatomi, menurut Laporan Audit Perawatan Kaki Diabetes Nasional 2014-2016, lebih dari 60.000 pengidap diabetes di Inggris diperkirakan memiliki luka kaki pada waktu tertentu. Prevalensi diabetes meningkat dan diperkirakan akan mencapai 4,9 juta orangorang di Inggris pada tahun 2035 dan hampir 1 juta orang saat ini dianggap tidak terdiagnosis tetapi menderita diabetes.

Dari kedua kasus tersebut pada pasien dengan pasca operasi laparatomi dan pada pasien luka ulkus diabetik, pemilihan balutan luka dapat bervariasi. Meskipun memiliki tahap-tahap yang dapat diidentifikasi, pada kenyataannya penyembuhan luka merupakan proses yang kompleks dan terus menerus, proses penyembuhan luka juga tidak selalu berjalan dengan lancar (Smeltzer \& Bare, 2010).
Wound dehiscence merupakan salah satu komplikasi luka post operasi yang paling serius. Beberapa penelitian memperlihatkan tingkat mortalitas dan morbiditas yang tinggi yaitu 3-35\% (Khorgami et al., 2012), dengan insiden wound dehiscence di dunia sekitar $0,4 \%$ $3,5 \%$ setelah pembedahan mayor abdomen dan dihubungkan dengan kematian sekitar $10 \%-45 \%$ (Ramshorst et al., 2010). Dampak dari wound dehiscence diantaranya meningkatkan stress pada pasien, viserasi, operasi ulang, gangguan body image, menurunkan kualitas hidup pasien, meningkatkan lama rawat dan biaya rawat lebih dari $300 \%$, meningkatkan anggaran kesehatan rumah sakit.

Manajemen bedah dengan sistem tekanan negatif atau negative pressure wound therapy (NPWT) ini dapat menjadi pendekatan baru untuk mengurangi komplikasi luka seperti wound dehiscence (Schurtz, Differding, Jacobson, Maki, \& Ahmeti, 2018), Penelitian penggunaan NPWT menunjukkan manfaat terapi yang potensial untuk mengurangi komplikasi luka pada pasien ginekologi onkologi yang menjalani operasi laparatomi dan berisiko tinggi wound dehiscence (Lynam, Mark, \& Temkin, 2016). 
RSUP Dr. Hasan Sadikin dapat mencapai kurang lebih 50 operasi setiap bulannya yaitu sekitar 0,4\%-1,13\%. Pada tahun 2011 sampai 2014 ditemukan kurang lebih 252 kasus abdominal wound dehiscence (Djaya, Rudiman, \& Lukman, 2012).

NPWT sudah menjadi teknik perawatan yang kerap dilakukan di RSUP Dr. Hasan Sadikin. Dari latar belakang tersebut menunjukan bahwa kejadian operasi laparatomi dan ulkus kaki diabetik dari tahun ke tahun mengalami peningkatan, begitu juga dengan risiko terjadinya wound dehiscence. Oleh karena itu, perawat perlu memberikan rencana tindakan keperawatan khususnya dalam memberikan implementasi untuk menurunkan dan mengurangi gangguan integritas kulit serta risiko infeksi, agar asuhan keperawatan yang diberikan komprehensif sesuai dengan evidence based terkini.

\section{Metode}

Studi kasus ini dilakukan diruang Kemuning Lantai 5 RSUP Dr. Hasan Sadikin Bandung. Setelah mendapat izin untuk melakukan studi kasus, observer melakukan identifikasi pasien yang sesuai dengan kriteria inklusi dan memberikan informed consent. Selanjutnya melakukan pengumpulan data primer dan sekunder (rekam medis pasien), data primer meliputi pengumpulan data demografi, observasi karakteristik luka, dan mengkaji faktorfaktor wound dehiscence. Data demografi meliputi jenis kelamin, usia, status marital, pendidikan, lama sakit, diagnosa, LOS, jenis tindakan perawatan luka, dan lokasi luka. Data karakteristik luka meliputi ukuran, warna dasar luka, kedalaman, jenis eksudat, produksi eksudat, kondisi kulit sekitar luka (intak, temperature, edema, sensasi nyeri, komplikasi), terapi, dan frekuensi ganti balutan instrument yang digunakan berdasarkan pengembangan konsep pengkajian luka menggunanakan metode DESIGN (Deep, Eksudat, Size, Infection, Granulasi, Nekrotik) (Sanada et al, 2004) dan mengembangakan instrument pengkajian luka yang digunakan diruangan Kemuning Lt.5 RSUP Dr. Hasan Sadikin. Data faktor-faktor wound dehiscence sesuai dengan tinjauan jurnal meliputi jenis operasi (Ningrum, Mediani, \& H.P, 2017), nilai albumin (Murtutik \& Suwarni, 2013), haemoglobin (Sivender et al., 2015), status nutrisi (Sivender et al., 2015), penyakit penyerta (Kusumayanti, Devi, Dian, \& Astriani, 2015), mobilisasi (Ditya, Zahari, \& Afriwardi, 2016), dan infeksi luka operasi (Van Ramshorst et al., 2010). Kriteria inklusi yang akan digunakan yaitu responden dengan usia $>18$ tahun, post operasi dengan infeksi akut, infeksi luka post operasi < 3 minggu (Maddineni et al., 2015), dan terpasang NPWT. Sampel pada studi kasus ini terdiri dari 2 orang pasien yaitu $\mathrm{Ny}$. A (pasien 1) dengan diagnosa medis wound dehiscence post colostomy + fistula retrovaginal dan Tn.T (pasien 2) dengan diagnosa medis ulkus pedis DM tipe 2 post amputasi pedis digiti 5 dan debridement.

\section{Hasil dan Pembahasan}

Pasien 1 (Ny. A) 51 tahun, datang ke RS Hasan Sadikin pada tanggal 30 November 2019 dengan keluhan keluar cairan bernanah bercampur feses lewat jalan lahir. Pasien dirawat di ruang Alamanda selama 1 hari. Pasien terdiagnosa fistula retrovaginal dan direncanakan untuk tindakan hartman procedure dan repair fistula sehingga pasien pindah ke ruangan kemuning 5 kamar 3 bed 4. Satu minggu SMRS pasien post operasi histerektomi di RS Santosa dengan mioma uteri. Tanda vital 
awal masuk ruangan Kemuning Tekanan darah 130/70 $\mathrm{mmHg}$, frekuensi pernapasan $20 \mathrm{x} / \mathrm{mnt}$, frekuensi nadi $90 \mathrm{x} / \mathrm{mnt}$, suhu $36,5^{\circ} \mathrm{C}$. Satu minggu post tindakan repair fistula dan hartman procedure pasien mengalami tanda-tanda infeksi diantaranya keluar pus dari jahitan post op dan terjadi dehisensi pada luka operasi. Sehingga dokter bedah digestif memutuskan untuk perawatan luka terbuka perawatan selanjutnya menggunakan metode NPWT pada tanggal 15 November 2019.

Pasien 2 (Tn. T) berusia 48 tahun, klien masuk RS Hasan Sadikin Bandung pada tanggal 12 November 2019 pukul 05.00 WIB dengan keluhan nyeri pada area kaki kiri yang luka, klien terlihat lemas, pada saat dilakukan pemeriksaan di IGD diketahui Tekanan darah 110/60 mmHg, frekuensi nadi $80 \mathrm{x} /$ menit, frekuensi pernapsan $27 \mathrm{x} /$ menit, suhu $37,5^{\circ} \mathrm{C}$, GDS $185 \mathrm{mg} / \mathrm{dl}$. Klien mengalami penyakit diabetes mellitus tipe 2 kurang lebih 5 tahun yang dan selalu berobat secara teratur. Sekitar 2 bulan yang lalu kaki kiri klien tersandung sehingga menimbulkan luka sampai dengan menjadi kehitaman setelah 1 minggu kejadian. Klien masuk RS
Kebon Jati untuk melakukan perawatan kaki dan berakhir harus amputasi pada jari kaki manis sebelah kiri. Setelah 2 minggu kepulangan dari RS Kebon Jati, luka kaki klien dirawat dirumah tapi kondisinya semakin buruk, sehingga harus dirujuk ke RSHS. Selain keluhan diatas klien mengeluhkan sesak nafas yang tidak kunjung hilang, hasil pemeriksaan diketahui nilai AGD pada tanggal 13 November 2019

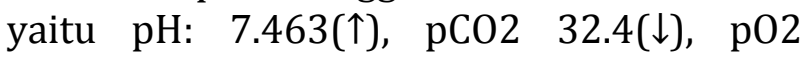

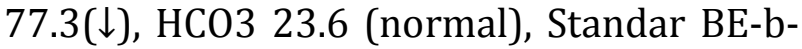
$0.6(\downarrow)$, Saturasi $0297 \%$ (normal). Pada tanggal 17 November 2019 klien dilakukan tindakan amputasi jari kaki digiti kelima, debridemen dan pemasangan NPWT. Hasil USG dopler diketahui Uncompressible vena poplitea kiri suatu deep vein thrombosis pada vena poplitea kiri disertai thrombus intralumen. Dicurigai Stenosis setinggi arteri dorsalis pedis kiri. Tidak tampak tanda-tanda stenosis arteri femoralis kiri, arteri poplitea, arteri tibialis anterior, dan posterior kiri. Tidak tampak tanda-tanda deep vein thrombosis vena femoralis kiri. 
Tabel 1

Data Demografi

\begin{tabular}{|c|c|c|}
\hline Data & Pasien 1 & Pasien II \\
\hline Nama & Ny.A & Tn.T \\
\hline Jenis Kelamin & Perempuan & Laki-laki \\
\hline Diagnosa & $\begin{array}{l}\text { Wound dehiscence post } \\
\text { colostomy + fistula retrovaginal }\end{array}$ & $\begin{array}{l}\text { Ulkus pedis DM tipe } 2 \text { post amputasi } \\
\text { pedis digiti } 5 \text { dan debridement }\end{array}$ \\
\hline LOS & 23 hari & 16 hari \\
\hline Usia & 51 tahun & 48 tahun \\
\hline Status & Menikah & Menikah \\
\hline Pendidikan & SD & Sarjana \\
\hline Lama Sakit & 1 bulan & 5 tahun \\
\hline Lokasi Luka & Abdomen & Ekstremitas bawah kiri \\
\hline Treatment & NPWT & NPWT \\
\hline
\end{tabular}

Responden studi kasus pada tabel 1 terdiri dari satu orang wanita berusia 51 tahun dan seorang pria berusia 48 tahun. Menurut penelitian (shamary 2012; Ningrum, Mediani, \& H.P, 2017) kejadian wound dehiscence sebagian besar (72\%) terjadi pada laki-laki dibanding perempuan $(27,3 \%)$. Hal ini dikaitkan dengan kebiasaan merokok yang cenderung banyak dilakukan oleh laki-laki dimana efek dari merokok dapat menghambat proses penyembuhan luka. Menurut (Abbas \& Hill, 2009) merokok merupakan salah satu faktor utama kejadian wound dehiscence diektahui didalam penelitiannya dengan mengamati wound dehiscence pada insisi abdominal bagian tengah klien yang mempunyai riwayat merokok mengalmi perbedaan tingkat perbaikan luka lebih rendah daripada klien dengan riwayat tanpa merokok dengan nilai $p=0.0002$ dan $O R: 3.7$.

Menurut (Departemen kesehatan RI 2009 dalam al-amin 2017), Pasien 1 dan pasien 2 termasuk pada kategori masa lansia awal (46-55 tahun), dikatikan pada karakteristik pasien kejadian wound dehiscence lebih sering terjadi pada usia di atas 40 tahun, hal ini mungkin terletak pada kerusakan mekanisme perbaikan jaringan pada usia lanjut, terutama selama beberapa hari pertama dari proses penyembuhan dimana sistem kekebalan tubuh memiliki peranan penting. Perubahan fungsional berpengaruh buruk terhadap masuknya selsel dan senyawa yang penting untuk perbaikan jaringan (Van Ramshorst et al., 2010).

Semua pasien yang terlibat dalam penelitian ini telah menikah dengan berbagai latar belakang pendidikan. Satu pasien berlatar pendidikan SD sedangkan satu pasien berlatar belakang pendidikan sarjana. Durasi penyakit juga bervariasi dari yang 1 bulan terdiagnosis dan 5 tahun sudah terdiagnosis. Untuk Lama hari rawat pasien 1 yaitu 23 dengan riwayat perawatan dan pengobatan wound dehiscence membaik dengan riwayat tindakan pada hari ke 22 luka pada pasien 1 dilakukan hecting skunder, sedangkan untuk pasien 2 pada hari ke 16 klien dan keluarga meminta pulang paksa dengan riwayat luka belum ada perbaikan. Penelitian yang dilakukan oleh Nursiah (2010) di RSUD Labuang Baji Makasar terhadap pasien yang menjalani tindakan pembedahan laparatomi menyatakan bahwa lama perawatan singkat yaitu tujuh sampai 14 hari sebanyak 74,2\% dan lama perawatan jangka panjang (lebih dari 14 hari) sebanyak 25,8\%. 


\section{Tabel 2}

Faktor yang berhubungan dengan Wound Dehiscence

\begin{tabular}{|c|c|c|c|c|}
\hline \multirow{3}{*}{$\begin{array}{l}\text { Analisis } \\
\text { Faktor }\end{array}$} & \multicolumn{2}{|c|}{ Pasien 1} & \multicolumn{2}{|c|}{ Pasien II } \\
\hline & $15 / 11 / 2019$ & $20 / 11 / 2019$ & $17 / 11 / 2019$ & $22 / 11 / 2019$ \\
\hline & Pre NPWT & H+6 NPWT & Pre NPWT & H+6 NPWT \\
\hline Jenis Operasi & Elektif & Elektif & Elektif & Elektif \\
\hline Albumin & $1.4 \mathrm{~g} / \mathrm{dL}$ & $1.65 \mathrm{~g} / \mathrm{dL}$ & $2.13 \mathrm{~g} / \mathrm{dL}$ & $2.10 \mathrm{~g} / \mathrm{dL}$ \\
\hline Hemoglobin & $8.9 \mathrm{~g} / \mathrm{dL}$ & $9.9 \mathrm{~g} / \mathrm{dL}$ & $9.7 \mathrm{~g} / \mathrm{dL}$ & $9.3 \mathrm{~g} / \mathrm{dL}$ \\
\hline IMT & 22.08 & 22.08 & 19.66 & 19.66 \\
\hline Penyakit & Tidak ada & Tidak ada & DM & DM \\
\hline Penyerta & & & & \\
\hline Mobilisasi & Imobilisasi & Imobilisasi & Imobilisasi & Imobilisasi \\
\hline $\begin{array}{l}\text { Infeksi luka } \\
\text { operasi }\end{array}$ & Ada & Ada & Ada & Ada \\
\hline
\end{tabular}

Pada kedua kasus pada pasien 1 dan pasien 2 jenis operasi yang dilakukan yaitu bersifat elektif, dimana jenis ini merupakan suatu tindakan bedah yang dilakukan terjadwal dengan persiapan serta dilakukan pada pasien dengan kondisi baik, bukan gawat darurat. Menurut Ningrum et al., (2017) kejadian wound dehiscence lebih tinggi prevalensinya pada jenis tindakan operasi emergensi atau cito daripa jenis tindakan elektif, sebesar $78 \%$.

Berdasarkan hasil observasi yang dilakukan diketahui nilai hemoglobin pasien 1 yaitu $8.9 \mathrm{~g} / \mathrm{dl}$ dan pada pasien 2 yaitu 9.7 $\mathrm{g} / \mathrm{dl}(<10 \mathrm{~g} / \mathrm{dl})$ termasuk dalam kategori anemia atau batas nilai hemoglobin kurang dari normal. Hal tersebut sejalan dengan penelitian Aksamija, Mulabdic, Rasic, \& Aksamija (2016) dengan metode retrospektif pada pasien yang mendapatkan tindakan bedah laparatomi disertai dengan wound dehiscence di clinical center university of Sarajevo dari bulan januari 2013 sampai dengan 1 januari 2016 dietahui angka kejadian anemia sebesar $43 \%$. Menurut Van Ramshorst et al., (2010) kejadian anemia dihubungkan dengan meningkatnya stress perioperatif, tranfusi darah dan menurunnya oksigenasi ke jaringan dimana kesemuanya mempengaruhi sistem imun dan proses penyembuhan luka.

Kejadian wound dehiscence pada pasien 1 tidak disertai dengan penyakit penyerta, sedangkan pada pasien 2 disertai dengan penyakit diabetes melitus. Diabetes mellitus mempengaruhi microvaskular yang menyebabkan menurunnya perfusi ke jaringan dan penyakit pulmonal menyebabkan hipoksia jaringan yang mereduksi sintesa kolagen dan mekanisme kerja neutrophil dalam membunuh mikroorganisme yang secara keseluruhan memperburuk kondisi pasien (Kusumayanti et al., 2015). Pasien mempunyai penyakit penyerta yang mengganggu status vaskuler maka berhubungan erat dengan pengangkutan atau penyebaran oksigen yang adekuat ke seluruh lapisan sel yang merupakan unsur penting dalam proses penyembuhan luka, sehingga penerapan NPWT akan kurang efektif. Derek et al (2012) yang menggunakan metode penelitian RCT dengan tujuan untuk mengevaluasi efek dari terapi tekanan tekanan negatif (NPWT) pada pasien bedah tertutup dengan penyakit penyerta. Hasil penelitian menunjukkan bahwa terdapat peningkatan infeksi dan wound dehiscence 
pasca operasi yang signifikan pada pasien dengan multipel komorbiditas (penyakit penyerta) dibandingkan dengan pasien yang tidak memiliki penyakit penyerta.

Pada pasien 1 dan 2 memiliki infeksi pada luka yang dialami pasien. Penelitian yang dilakukan oleh Izadpanah, et al (2017) intervensi NPWT memungkinkan berhasil menyembuhan $73 \%$ pada pasien. Hasil penelitian ini menunjukkan bahwa manifestasi infeksi yang tertunda, kadar CRP darah yang tinggi, adanya spesies bakteri yang sedang menginfeksi dalam terapi meningkatkan risiko kegagalan NPWT.

Status nutrisi pada pasien 1 dan 2 masih dalam rentang IMT normal yaitu 22,08 dan 19,66. Meylani et al. (2012) mengatakan bahwa wound dehiscence banyak terjadi pada pasien dengan gizi buruk 59\% ( $\mathrm{p}=0,02)$ dan banyak terjadi pada pasien dengan BMI > 25 yaitu sebanyak 13\% ( $\mathrm{p}=0,02)$ sedangkan pada pasien dengan BMI < 18,5 yaitu $13 \%$ ( $\mathrm{p}=$ 0,03). Pasien yang mengalami obesitas memiliki jaringan lemak yang sangat rentan terhadap infeksi selama fase pembedahan sehingga rentan mengalami infeksi luka operasi (Sivender et al., 2015).

Pasien 1 dan 2 mengalami hipoalbumin dengan rentang nilai albumin < $3 \mathrm{mg} / \mathrm{dl}$. Menurut (Hitesh \& Pratik, 2014) hipoalbuminemia berkontribusi memperpanjang fase inflamasi dan fibroplasia, proliferasi, proteoglycan dan sintesis kolagen, neoangiogenesis dan proses remodeling serta penurunan kekebalan tubuh. Pada kondisi hipoalbuminemia, kondisi hipoalbumin terjadi perubahan dalam metabolisme sitokin terutama aktivitas interleukin-1 yang terganggu dan kegagalan pada sistem komplemen. Oleh karena itu, pada kondisi hipoalbuminemia umumnya sering ditemukan infeksi luka operas dan menjadi salah satu faktor risiko untuk terjadinya dehiscence. Kadar albumin serum rendah juga menjadi prediktor independen dari kegagalan untuk mencapai primary fascial closure (PFC) ketika mengendalikan proses penyakit primer, keparahan penyakit akut, dan beban transfusi (Loftus et al., 2018). Hipoalbuminemia berkontribusi memperpanjang fase inflamasi dan fibroplasia, proliferasi, proteoglycan dan sintesis kolagen, neoangiogenesis dan proses remodeling serta penurunan kekebalan tubuh (P, H, J, \& G, 2015)

Pasien 1 dan pasien 2 mempunyai hambatan untuk melakukan mobilisi, banyak faktor yang mendasari kesulitan mobilisasi diantaranya klien mempunyai anggapan jika bergerak akan sakit, tidak mengetahui manfaat mobilisasi terkait perkembangan dan perbaikan luka. Pengaruh mobilisasi setelah pasca operasi laparatomi sangat besar manfaatnya dalam proses penyembuhan luka, karena mobilisasi dapat meningkatkan sirkulasi di daerah insisi sehingga akan meningkatkan transfortasi zat-zat esensial yang berperan dalam proses penyembuhan luka (Ditya et al., 2016). 
Tabel 3

\section{Pengkajian Luka}

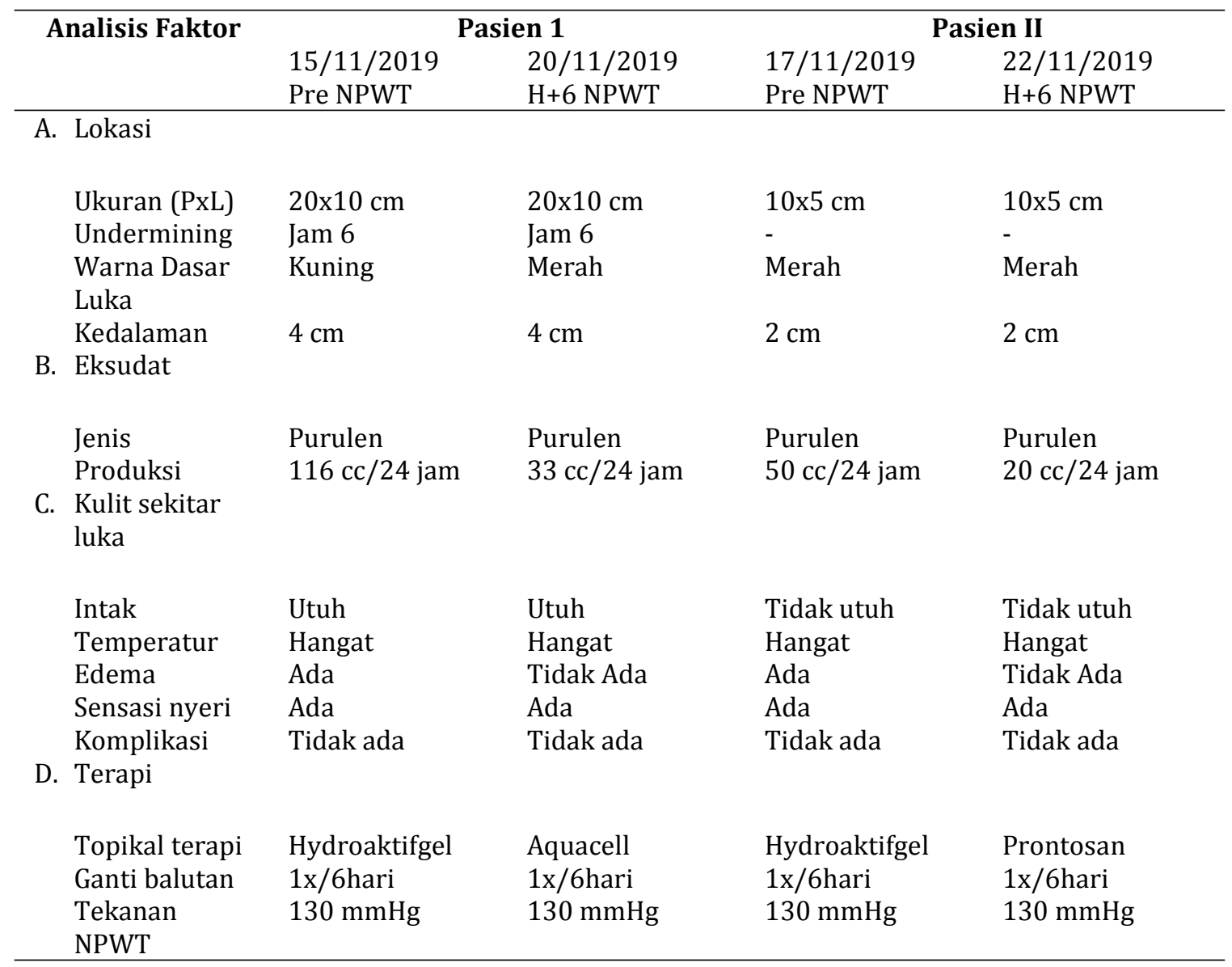

Fase penyembuhan luka menurut Maryunanik (2013) fase pertama adalah koagulasi/hemostasis. Pada pasien 1 dan pasien 2 sudah terjadi tahap koagulasi dimana pasien dapat menghentikan dan mengontrol perdarahan dari pembuluh darah yang terluka, terjadi pembentukan bekuan darah oleh trombosit dan tromboplastin.

Fase ke dua yaitu fase inflamasi (peradangan) dimulai 1 jam setelah luka sampai hari kedua atau ketiga. Berdasarkan lokasi luka, pasien 1 memiliki ukuran luka 20x10 cm sedangkan pasien $210 \times 5 \mathrm{~cm}$. Undermining pada luka pasien 1 menunjukkan arah jam 6 sedangkan pada pasien 2 tidak terarah. Kedalaman luka pada pasien 1 yaitu $4 \mathrm{~cm}$ dan pada pasien 2 yaitu $2 \mathrm{~cm}$. Pada pasien 1 dan 2 sudah terjadi fase inflamasi dengan ciri-ciri kemerahan, terdapat purulen dengan produksi yang berkurang dari hari pertama NPWT sampai hari ke 6 NPWT antara pasien 1 dan pasien 2. Berdasarkan kulit sekitar luka pada pasien 1 intak utuh sedangkan pasien 2 intak tidak utuh dimana jari kaki kiri klien sudah ada yang terpotong akibat lukanya. Terdapat bengkak/edema pada saat pemasangan NPWT dan pada NPWT hari ke 6 sudah tidak terdapat edema, pasien 1 dan 2 terdapat nyeri, disekitar luka teraba hangat. Pada pasien 1 dan 2 tidak ada 
komplikasi, sesuai dengan penelitian yang menyebutkan bahwa dengan NPWT tingkat komplikasi luka dapat dikurangi sepertiga pada wanita berisiko tinggi menjalani laparotomi untuk keganasan ginekologi (Lewis et al., 2014). Memanjangnya fase inflamasi menyebabkan peningkatan jumlah MMP di area luka diabetik dan secara bersamaan menurunkan jumlah inhibitornya. Penelitian Liu et al., 2009 menunjukkan adanya peningkatan jumlah MMP-9 dan penurunan jumlah TIMP-1 pada pasien dengan luka kaki diabetik kronis. Kondisi ini dapat meningkatkan proses degradasi matriks di area luka dan kerusakan jaringan yang berkontribusi pada penyembuhan luka yang memanjang.

Fase ketiga yaitu fase proliferasi, apabila tidak ada interaksi dan kontaminasi pada fase inflamasi, maka akan cepat terjadi fase proliferasi. Terjadi hari ke 2 atau ke 3 setelah luka, terdiri dari angiogenesis merupakan pembentukan pembuluh darah baru dengan bantuan sel epithelial dan fibroblast. Deposisi kolagen merupakan pembentukan jaringan kolagen sebagai pembentuk jaringan ikat pada luka berlangsung sampai minggu ke 2 dan ke 4 . Pembentukan granulasi terjadi pada hari ke 2 sampai ke 5 setelah luka dibentuk oleh fibrolas yang mengalami proliferasi dan maturasi. Epitelisasi dimana jaringan granulasi memudahkan terjadinya reepitelisasi terjadi hari ke 5. Kontraksi merupakan bagian yang penting pada penyembuhan luka terjadi setelah hari ke 7 dan melibatkan myofibroblast. Warna dasar luka pada saat pemasangan NPWT pada pasien 1 berwarna kuning dan pada hari ke 6 setelah NPWT berwarna merah atau sudah terjadi granulasi, sedangkan warna dasar luka pada saat pemasangan NPWT pada pasien 2 berwarna merah (granulasi) dan pada hari ke 6 setelah NPWT berwarna merah pucat.
Perbandingan data mengenai faktorfaktor yang berkontribusi terhadap kejadian wound dehiscence pada pasien 1 dan pasien 2 menggambarkan data yang hampir sama, pada pasien 1 terjadi perkembangan luka sesuai tahapan dan berkembangan dengan baik. Namun perbaikan luka pada pasien 2 belum terlihat, pada pre pemasangan NPWT dasar luka terlihat berwarna merah (granulasi), tetapi setelah 6 hari pemasangan NPWT dasar luka menjadi warna pink, diameter luka menjadi bertambah. Terhambatnya perkmbangan luka pada Tn.T terjadi karena kondisi hiperglikemik atau kadar glukosa tinggi > $250 \mathrm{mg} / \mathrm{dl}$ pada pasien 2 dengan diabetes melitus dapat menghambat faktor penyembuhan luka ditambah leukosit yang meningkat ketika infeksi akan mempengaruhi penyembuhan luka Smeltzer \& Bare (2002). Selain itu vaskularisasi menjadi faktor lainya yang perlu diperhatikan hasil usg dopler menunjukan Uncompressible vena poplitea kiri ec.suatu deep vein thrombosis pada vena poplitea kiri disertai thrombus intralumen. Mencurigai stenosis setinggi arteri dorsalis pedis kiri. Gangguan pembuluh darah pada luka kaki diabetes dapat terjadi antara lain gangguan pembuluh darah arteri dan vena (Clayton, Warren \&Elasy (2009) dalam Tarwoto 2012). Gangguan pembuluh darah arteri perifer merupakan faktor yang berkonstribusi terhadap perkembangan luka kaki diabetes sampai 50\% kasus. Kondisi ini akan berpengaruh pada arteri tibialis dan arteri peroneal otot betis. Disfungsi sel endotel dan abnormalitas sel otot polos berkembang pada pembuluh darah arteri sebagai konsekuensi status hiperglikemia yang persisten. Terjadi penurunan fungsi matriks ekstraseluler pembuluh darah yang memicu terjadinya stenosis lumen arteri akhirnya mengakibatkan iskemia pada ekstremitas bawah dan meningkatkan risiko luka kaki 
diabetes. Evaluasi status vaskuler pasien dengan luka kaki diabetes dapat dilakukan dengan pemeriksaan non invasif seperti menggunakan doppler vaskuler untuk menilai ABI (ankle brachial index) sirkulasi pembuluh darah arteri dan vena. Untuk pemeriksaan non invasif adalah venography dan arteriography.

Selain itu faktor suplai oksigen menjadi peran penting dalam dukungan perbaikan luka, pada pasien 2 mengeluhkan sesak nafas disertai dengan hasil lab AGD diketahui pada tanggal 13 november 2019 pH: $7.463(\uparrow), \quad$ pCO2 $32.4 \quad(\downarrow), p 02 \quad 77.3$ $(\downarrow), H C O 323.6$ (normal), Standar BE-b -0.6 $(\downarrow)$, Saturasi $0297 \%$ (normal). Menurut hasil penelitian (Schreml et al., 2010) diketahui dalam perbaikan luka pasokan energy biokimia menajdi kebutuhan dasar. Oksigen sangat penting untuk produksi energy biologis (missal; adenosine triphosphate, ATP), glikolisis aerob, siklus asm sitrat dan oksidasi asam lemak. Oksigen diperlukan untuk proses reparative seperti proliferasi sel, pertahanan bakteri, angiogenesis dan sintesis kolagen.

\section{Simpulan}

Negative Pressure Wound Therapy (NPWT) atau biasa disebut dengan TNP (Topical Negative Pressure) merupakan terapi non farmakologis yang digunakan dalam penatalaksanaan luka akut maupun kronik, meliputi pressure ulcer (dekubitus), luka diabetik, maupun luka karena trauma. Menurut Penggunaan NPWT dilakukan dengan cara memberikan tekanan negatif lokal di permukaan luka.

Perbaikan luka pada pasien 1 post pemasangan NPWT terlihat derajat perbaikan yang signifikan ditandai dengan adanya granulasi, pengurangan eksudat sesuai dengan konsep tahapan perbaikan luka. Namun pada pasien 2 pada post 6 hari pemasangan NPWT belum terlihat adanya perbaikan yang signifikan ditandai dengan belum terlihatnya adanya granulasi pada luka tersebut keterlambatan perbaikan luka pada pasien 2 dikaitkan dengan faktorfaktor terkait diantanya faktor penyakit penyerta (diabetes mellitus tipe 2), status vaskularisasi dan oksigenasi.

\section{Daftar Pustaka}

Abbas, s. M., \& hill, a. G. (2009). Smoking is a major risk factor for wound dehiscence after midline abdominal incision; case?control study. $A n z$ journal of surgery, 79(4), 247-250. Https://doi.org/10.1111/j.14452197.2009.04854.x

Aksamija, g., mulabdic, a., rasic, i., \& aksamija, l. (2016). Evaluation of risk factors of surgical wound dehiscence in adults after laparotomy. Medical archives (sarajevo, bosnia and herzegovina), 70(5), 369-372. Https://doi.org/10.5455/medarh.201 6.70.369-372

Al Amin, M. (2017). Klasifikasi Kelompok Umur Manusia Berdasarkan Analisis Dimensifraktal Box Counting Dari Citra Wajah Dengan Deteksi Tepi Canny. MATHunesa, 2(6).

Derek, M., Jesse, G., Mathew, E., Kyle, X, John, S., dan Christopher, A. 2012. Negative Pressure Wound Therapy for At-Risk Surgical Closures in Patients With Multiple Comorbidities: A Prospective Randomized Controlled Study

Ditya, r., zahari, a., \& afriwardi. (2016). Artikel penelitian hubungan mobilisasi dini dengan proses penyembuhan luka pada pasien pasca laparatomi di 
bangsal bedah pria dan wanitarsup dr. M. Djamil padang wira. Jurnal kesehatan andalas, 5(3), 724-729.

Djaya, W., Rudiman, R., \&Lukman, K. (2012) Efek Oksigen Konsentrat Tinggi Paskaoperasi Laparatomi terhadap Tingkat Infeksi Luka Operasi. $M K B B$, 40(3).

Hitesh, k., \& pratik, v. (2014). Factors affecting post wound complications. International archives of integrated medicine, 2(1), 71-75.

Izadpanah, K., Hansen, S., Six-merker, J., Helwig, P., Südkamp, N. P., \& Schmal, H. (2017). Factors influencing treatment success of negative pressure wound therapy in patients with postoperative infections after Osteosynthetic fracture fixation, 1-10. https://doi.org/10.1186/s12891-0171607-0

Kemenkes RI. (2013). Standar Pelayanan Minimal Rumah Sakit. Jakarta : Kemenkes

Khorgami, Z., Shoar, B., Laghaie, B., Aminian, A., Araghi, N.H., \& Soroush, A. (2012). Prophylactic retention suture in midline laparotomy in high risk for wound dehiscence : a randomized controlled trial. Journal of Surgical Research, xxx, E1-E6

Kusumayanti, devi, n. L. P., dian, n. M., \& astriani, l. P. N. (2015). Faktor-faktor yang berpengaruh terhadap lamanya perawatan pada pasien pasca operasi laparatomi di instalasi rawat inap brsu tabanan. Journal coping, 3(1). Https://doi.org/10.1017/cbo9781107 415324.004
Lewis, l. S., convery, p. A., bolac, c. S., valea, f. A., lowery, w. J., \& havrilesky, l. J. (2014). Cost of care using prophylactic negative pressure wound vacuum on closed laparotomy incisions. Gynecologic oncology, 132(3), 684-689. Https://doi.org/10.1016/j.ygyno.2014. 01.014

Lynam, s., mark, k. S., \& temkin, s. M. (2016). Primary placement of incisional negative pressure wound therapy at time of laparotomy for gynecologic malignancies. 26(8), 1525-1529. Https://doi.org/10.1097/igc.0000000 000000792

Maddineni, n., koduru, s., surath, h., dakshina murthy, a. R., reddy, m., \& surath, a. (2015). Negative pressure wound therapy in orthopaedic post operative infections: role in implant retention and dead space management. Journal of $d r$. Ntr university of health sciences, $\quad 4(4), \quad 257$. Https://doi.org/10.4103/22778632.171743\

Maryunanik Anik, 2013, Step by StepPerawatan Luka Diabetes dengan Metode Perawatan Luka Modern, In Media, Bogor

Meilany, T. A., Arianto, A., Bausat, Q., Prihartono, J., \& Sjarif, D. R. (2012). Pengaruh Malnutrisi dan Faktor lainnya terhadap kejadian Wound Dehiscene pada Pembedahan Abdominal Anak pada Periode Perioperatif, 14(2).

Murtutik, l., \& suwarni, a. (2013). Hubungan kadar albumin dengan penyembuhan luka pada pasien post operasi laparatomy di ruang mawar rumah sakit slamet riyadi surakarta. Jurnal 
ilmu keperawatan indonesia, 1(1), 8097. Retrieved from http://download.portalgaruda.org/art icle

Ningrum, t. P., mediani, h. S., \& h.p, c. I. (2017). Faktor-faktor yang berhubungan dengan kejadian wound dehiscence pada pasien post laparatomi. Jurnal keperawatan padjadjaran, $5(2)$. Https://doi.org/10.24198/jkp.v5i2.45 5

P, k. H., h, v. P., j, p. N., \& g, m. J. (2015). Factors affecting post-operative post operative laparotomy wound complications. 2(1), 71-75.

Nursiah, Arfah Noer. (2010). Faktor-faktor yang berhubungan dengan lama hari rawat pada pasien pasca operasi laparatomi di rumah sakit umum daerah Labuang Baji Makasar. Skripsi tidak diterbitkan. Makasar Fakultas Kedokteran Universitas Hasanuddin.

Sanada, h., moriguchi, t., miyachi, y., ohura, t., \& nakajo, t. (2004). Reliability and validity of design, a tool that classifies pressure ulcer severity and monitors healing. Journal of wound care, vol 13, no, 13-18.

Schurtz, e., differding, j., jacobson, e., maki, c., \& ahmeti, m. (2018). Evaluation of negative pressure wound therapy to closed laparotomy incisions in acute care surgery. American journal of surgery, 215(1), 113-115. Https://doi.org/10.1016/j.amjsurg.20 17.08.009
Sivender, a., ilaiah, m., \& reddy, s. (2015). A clinical study on risk factors causing abdominal wound dehiscence and management. Iosr journal of dental and medical sciences ver. Iv, 14(10), 21. Https://doi.org/10.9790/0853141041823

Smeltzer \& Bare, 2002, Buku Ajar Keperawatan Medikal Bedah Brunner 7 Suddarth edisi 8. EGC: Jakarta

Smeltzer, S.C., \&Bare, B.G. (2010). Post operative nursing wound management. In Brunner \& Suddart's Textbook of medical- surgical nursing (12th ed.). Philadelphia:J.B. LippincottCompany

Tarwoto, Dkk. 2012. Keperawatan Medikal Bedah Gangguan Sistem Endokrin. Jakarta: Trans Info Medikal.

Ramshorst, G. H., Nieuwenhuizen., Hop, W.C.J., Arends, P., Boom, J., Jeekel, J., \& Lange, J.F. (2010). Abdominal Wound Dehiscence in Adults : Development and Validation of a Risk Model. World Journal Surgical, 34, 20-27. Doi : 10.1007/s00268- 009-0277-y

Van ramshorst, g. H., nieuwenhuizen, j., hop, w. C. J., arends, p., boom, j., jeekel, j., \& lange, j. F. (2010). Abdominal wound dehiscence in adults: development and validation of a risk model. World journal of surgery, 34(1), 20-27. Https://doi.org/10.1007/s00268-0090277-y 